\title{
Bringing sustainability to the heart of a university through teaching, research and service
}

\author{
Esra Gençtürk ${ }^{1}$ and M. Pinar Mengüç ${ }^{2, *}$ \\ ${ }^{1}$ Rector, Ozyegin University, Istanbul, Turkey \\ ${ }^{2}$ Director, Center for Energy, Environment and Economy, Ozyegin University, Istanbul, Turkey
}

\begin{abstract}
In this short paper, we summarize our targeted efforts at Ozyegin University in Istanbul, Turkey for establishing a sustainable research, teaching and learning environment. The University is striving to have highest level impact on sustainable education, energy, architecture, built environment, business and life-long learning practices. The strategic plan of the University puts the principles of sustainability at the cornerstone of its efforts, with the aim to aspire not only our students and staff, but also the community at large.
\end{abstract}

\section{Introduction}

Ozyegin University (OzU) was established in 2007 with the goal of becoming one of the leading research universities in Turkey [1]. The University had its first student intake in 2008. In 2012, it moved to its modern campus at Cekmekoy; one of the new suburbs of Istanbul. OzU have always had the vision to impact the society with innovation and entrepreneurship. The university-wide efforts on sustainability, both in scientific and practical sense, have made the university well known among the higher education institutes in Turkey as a visionary place to work and learn.

These efforts have paid off as OzU has consistently been ranked among the top ten list of the Entrepreneurial and Innovative University Index of Turkish Science and Technology Foundation (TUBITAK) since 2011 (out of more than 170 Universities in Turkey). This ranking is simply a reflection of faculty productivity in research as well as in patents and companies they have established. Among the grants received, those related to sustainable infrastructure and sustainable energy have considerably contributed to OzU's sustainability goals. To this end, six EU-FP7 and Horizon 2020 grants received and completed by Center for Energy, Environment and Economy (CEEE) is worth mentioning [2].

The teaching environment at $\mathrm{OzU}$ is also designed differently than many other universities as it starts with a coherent sustainability emphasis in the freshman curriculum, allowing all students to have a grounded awareness for the global and local sustainability goals. In addition, the Faculty of Social Sciences in general and its Psychology Department in particular are known for outstanding programs geared towards gender-equality at the University and in the Society. Several innovative energy courses were also introduced at the University over the years, including 'Zero Istanbul 2050' (chosen as one of the Global Initiatives by IBM) and the dual undergraduate and graduate level 'Sustainable Materials, Energy, and Systems' course co-organized by CEEE along with IMSAD, the largest umbrella NGO on construction and building materials in Turkey [2].

The University is also the lead contributor to the business world on establishing deep-rooted sustainable development goals for establishments of various sizes and at different sectors [3]. The launch of the Sustainable Development Forum at OzU in partnership with TUSIAD, the largest NGO for the Turkish Business World, is unique among the Turkish universities. More details are given below.

\section{Pursuing sustainability}

Ozyegin University has been emphasizing the principles of sustainable architecture, engineering, education, living and practices since it was established in 2007. Over the last ten years, several strong initiatives have been started by the University administration and by the faculty members which were aligned with the UN Sustainable Development Goals (SDG) even before the subsequent announcement of the SDGs [3].

The following seven SDG's have actively been pursued by OzU: SDG4: Quality Education; SDG 5: Gender Equality; SDG7: Affordable and Sustainable Energy; SDG 9: Industry, Innovation and Infrastructure; SDG 11: Sustainable Cities and Communities; SDG 13: Climate Action; and SDG 17: Partnerships to Achieve these Goals. The spirit of these goals has explicitly and implicitly influenced all the decisions made and the strategies formulated by the University so far. Below, we discuss specific OzU efforts geared towards Constructing a Green Campus, on Research and Teaching, and on Partnerships. We also list the specific Awards given to some of the University members for their contributions to the sustainability science and applications.

\footnotetext{
"Corresponding author: pinar.menguc@ozyegin.edu.tr
} 


\subsection{Constructing a green campus}

Since its first days, Ozyegin University has aimed to build a sustainable and exemplary education environment. The University built a modern campus in Cekmekoy, at the suburbs of Istanbul, in 2012. The first three buildings erected at the campus were all awarded with LEED certificates, showing the dedication of $\mathrm{OzU}$ to environmental sustainability. All other buildings were also built as sustainable and energy efficient buildings. In addition to LEED certificates, OzU also has ISO 14001 and OHSAS 18001 certificates.

The fourth academic building of $\mathrm{OzU}$ was constructed with more stringent rules than a LEED certificate would dictate. SCOLA building was designed and built as part of an European Union Framework Programme 7 (EU-FP7) project called NEED4B (New Energy Efficient Demonstration for Buildings) [4]. This major effort was conducted by Center for Energy, Environment and Economy (CEEE), which allowed the detailed and integrated engineering and architecture principles to be applied to the construction as well as to the operations of SCOLA building. These efforts are in line with the Sustainable Development Goals 7, 9 and 11 mentioned above. Currently, the SCOLA building is considered as one of the most energy efficient and sustainable buildings in Turkey [5].

Interestingly, the building constructed by the University after SCOLA, The Law School building, has become the second most efficient building on the campus although CEEE is not involved in the process. All engineers and architects involved in NEED4B project have applied their experiences effectively to the new construction. Through teaching by practice and example, OzU had another sustainable building, with very low carbon footprint. This action is indeed in line with the Sustainable Development Goals of 13 and 17.

The sustainable engineering efforts undertaken by the University are not limited to the academic buildings. Before the campus was built, the University Board of Trustees approved the construction of the Energy Distribution Center (EDS) in 2010 paving the way to centralized heating and cooling modalities. EDS is in the core of regional heating/cooling concept empahasized by the European Union FP7 and Horizon 2020 programs to achieve high energy performance on more than a single building. EDS at OzU makes the campus very efficient in energy use with very low carbon footptint.

Currently, the University is working on the construction of a signature School of Architecture building. This challenging, complicated, multi-purpose structure is being designed with explicit sustainability goals and expected to be an example educational building with high energy performance.

The sustainable energy concepts can be seen everywhere at the campus. There are solar panels to provide about $7 \%$ of the energy from the sun, and there are green roof systems to help the energy efficiency of all buildings. Several other new concepts developed by the CEEE researchers are also used in several buildings, as outlined in the next section. At Ozu, there is extensive water and waste management systems in place, which are inherent in the sustainable eco-system of the campus. With all these special buildings and initiatives, $\mathrm{OzU}$ is considered as the pioneer of innovative and sustainable higher-education institutions in Turkey.

\subsection{Education and research}

Ozyegin University has been prioritizing the depth and the breadth of education it provides in line with the principles of sustainability principles since it was established in 2007. The University has introduced various topics, engineering practices, campus operation modalities as well as integrated research projects which incorporated sustainable development goals in almost all fields. Both in regular class-room courses or as part of the research related courses, the University has a great interest in placing multi-, inter-and trans-disciplinary studies in all of its academic units. This strategy also creates and fosters an interdisciplinary atmosphere at the University, allowing faculty as well as students to think beyond their own specific fields of study.

Almost all departments at OzU include the sustainability vision into their curriculum, with the help of umbrella courses offered by the University. Probably the most unifying theme is due to the teaching of English in the University's School of Languages (SCOLA) [5]. The language of instruction at $\mathrm{OzU}$ is primarily English. SCOLA is responsible for preparing incoming students to have strong English communication skills. To this end, sustainability is designated as the substantive topic of one of the English courses which is mandatory for all $\mathrm{OzU}$ students. The instructors responsible with this course use academic as well as popular press articles addressing different aspects of sustainability. Later, students use this know-how in their advanced studies.

Sustainability is also covered at several other courses taught at $\mathrm{OzU}$ beyond the SCOLA curriculum. Some examples are listed below :

- Energy, Environment and Economy for Sustainable Istanbul 2050

- Sustainability in Higher Education

- Environmental Control

- Sustainable Design and Environment through Biomimicry

- Green Buildings and Sustainable Design

- Energy Efficient Building Design and Renovation

- Certificate Sustainability in Business

- Social Entrepreneurship, Social Innovation and Innovating Social Change

- Environmental Law

- Power management for Advanced Energy Storage Systems

- Ecology and Production of Food

- Sustainable Development for Hotels

- Ecotourism

- Energy Licenses

- Partnership in Energy Markets

- Renewable Energy \& Renewable Energy Law

- Sustainable Energy Materials and Systems: An Integrated Approach for Buildings. 
Beyond undergraduate courses and student projects, several graduate level research projects are also deeprooted in the principles of sustainability. These projects have clearly created a knowledge and awareness platform, improved the experience of the University members and revealed the needs of the research environment in especially at the local scale. Around 98 specific projects, which have been carried out so far at $\mathrm{OzU}$, are related to the 7 SDGs mentioned above. The University is continuously working on new initiatives and new courses to involve more students and faculty in the practicing towards these specific SDGs.

$\mathrm{OzU}$ students have to take part in social responsibility projects to meet the civic engagement requirement of their degrees. These activities are performed under a platform named Duyarl OZU (Sensitive OzU) which was founded by students in 2011 as a social initiative for developing volunteering opportunities. Several projects in different locations in and outside of Istanbul, Turkey has given students the chance of gaining awareness in social sustainability and helping others, such as children, elders, animals and environment.

The University has a focused effort on sustainable energy and infrastructure for building and cities. The research and development projects carried out by the Center for Energy, Environment and Economy (CEEE) have been supported through six major European Union grants received so far. One of them, as mentioned above, is the EU-FP7 Project called NEED4B [4]. This allowed, the University to have one of the most energy efficient buildings in Turkey. Another project conducted by CEEE is to renovate a major hospital building in Aydin Province of Turkey, at Adnan Menderes University. The third major EU Grant to CEEE is TRIBE project funded by the Horizon 2020 program, which allowed the researchers to study human-building interactions in depth. This research brings the sustainable energy concepts to the user level and aims to have significant reduction in carbon footprint by increasing the awareness of building occupants. The concepts developed from this TRIBE project is currently applied to the Engineering Building at OzU [2].

All these concepts can be most useful if the knowhow developed can be transferred to technicians who actually build the required infrastructure to make buildings more energy efficient and comfortable. CEEE is working with three local vocational schools to improve their curriculum to achieve these. Note that all these efforts by CEEE can be listed under SDGs 4, 7, 9, 11,13 and 17 .

Due to these coordinated and structured emphases on sustainability at $\mathrm{OzU}$ as related to sciences, engineering, architecture, law, and societal issues, the students, faculty and staff have developed quite high level of awareness and knowledge on the topic. As the members apply and share this knowledge within their daily routines, a chain of additional sustainable practices naturally follow. This has resulted in an unifying grass roots culture around the campus on what sustainability is and how it can be internalized in everything we do.

\subsection{Partnership}

Ozyegin University believes in the mission of serving the public by generating knowledge and sharing it. In this direction, $\mathrm{OzU}$ cares about the integration of partnerships into education and research. The University has developed several initiatives with professionals and stakeholders. Among them, SKF (Sustainable Development Forum) founded in 2015 with the collaboration of TUSIAD (Turkish Industry and Business Association) focuses mainly on sustainable development in the business world within the framework of SDGs. By being a part of this global agenda, OzU's objective is to build a strong dialogue, support the business world with its unique research competences while nourishing and directing its research areas through the developments and needs of the business world.

$\mathrm{OzU}$ has a broader participation on societal problems related to Istanbul and Turkey. In 2010, OzU CEEE has organized the first Workshop on Istanbul'2050, which brought together 80 people from all walks of society [6]. It was also attended by the EU Energy Ministry, and at the end the Workshop highlighted the challenges Istanbul has been facing. Interestingly, 'the protection of the soul of Istanbul' was found to be the most pressing issue; in essence this was the prelude to 'sustainable cities' emphasis of the United Nations, before the UN SDGs were declared. Later in 2011, CEEE has organized a Conference on Integrated Engineering and Architecture for Sustainable Buildings. It was co-funded by the US National Science Foundation (NSF) and the Turkish Science and Technology Council (TUBITAK), and had more than 30 lectures from both countries. Since then CEEE is routinely organizing conferences and workshops on sustainable energy and human-building interactions for sustainable buildings. Since 2017, CEEE is also involved with the major effort called Sustainable Anatolia, which is organized in the city of Ilgaz, in Central Turkey. This year, OzU CEEE will be one of the main sponsors of the event.

OzU Technology Transfer Office (TTO) was established in 2013 to provide support to all projects and the intellectual properties of OzU faculty [7]. When established, OzU TTO was one of the ten initial such offices supported by TUBITAK. Although their effort is not related to SDGs directly, the presence of a well funded TTO at OzU is important for the establishment and continuity of a sustainable research environment at the University.

Sustainability requires innovation and determined leadership. With this, the University has recently opened a new building, fondly named $\mathrm{OzU}-\mathrm{X}$, where innovation and entrepreneurship are pursued by the students and the faculty. The University has established a partnership with General Electric (GE), to develop further initiatives, which will enhance the sustainability and societal impact of research conducted by $\mathrm{OzU}$ members. In fact these effort are paying off, as OzU received the first Industry 4.0 funding from the Ministry of Science, Industry and Technology [8]. The project "Digital Transformation of SMEs in Turkey through Establishment of the Industry 4.0. Competence Center" presented under the 
"Manufacturing Industry" category was selected among the priority projects to receive funding for the second phase of the Competitive Sectors Programme run jointly by the Turkish Government, the General Directorate of European Union and Foreign Affairs, and the EU Financial Programs Department

\subsection{Awards to show the efforts}

Detailed and dedicated studies of several OzU members who work on the general framework of sustainability have been rewarded with several awards both in local and global scale. The University was ranked quite high in Greenmetric rankings even though it is a very Below are some of the most significant awards received by the OzU researchers and the students:

- 2016: Özyeğin University was included in the annual report of international sustainable campus best practices as one of the 19 universities with selected cases on "Capacity Building" and "Innovation for Best Practices" reflecting how universities are developing their sustainability skills and building capacities in collaboration with corporate partners.

- 2017: Özyeğin University was featured as one of the best practice examples by the International Sustainable Campus Network (ISCN) and Global University Leader Forum (GULF), which is the academic platform of World Economic Forum, and included in the annual report of 2017 "Educating for Sustainability" in recognition of its current practice "Innovative Three-Layered Sustainability Education for the Business World".

- 2017: A team by Elif Gizem Tunçel and Ebru Tatar, two women graduate students at the Mechanical Engineering Department, who are also among the CEEE researchers, have become one of the twelve teams to be invited to the finals of "Go Green in the City" competition organized by Schneider. They were anong 24 individuals selected out of 19,722 competing worldwide. Working with Professor M. P. Mengüç, Ebru and Elif Gizem have also received the "Women in Business Award" at the ceremony in Paris, France [9].

- 2017: Azadeh Didari, a post-doctoral fellow at CEEE was chosen to receive the Elsevier/JQSRT Raymond Viskanta Young Scientist Award, which is presented to only one researcher each year world-wide [10]. The award ceremony was held at KAIST, Daejeon, Korea. Her work is on sustainable energy at nanoscales. She received her $\mathrm{PhD}$ from $\mathrm{OzU}$ under M.P. Mengüç.

\section{Future plans}

The University has been preparing its new 5-year strategic plan, which will be in effect by the 2018-2019 academic year. The University Administration and the Board of Trustees have agreed unanimously on making sustainability one of the pillars of University. To this end, the University plans to develop more inter-, multiand trans-disciplinary studies that combine the efforts of different academic and administrative units. These new initiatives will not only cover the academic curriculum but also include specific action plans to elevate the research output and impact to a higher level.

Two OzU buildings are planned to have further contributions to the University sustainability efforts. As mentioned above, OzU-X, a new open innovation coworking hub opened at the heart of the campus Also, a new Architecture Building is being constructed. This building is designed by combining all sustainable engineering-architecture principles with the sustainable energy emphasis.

The University is continually reaching out to the world outside of the campus to transfer the new knowledge developed by its faculty and students to different sectors and businesses. Collaborations with TUSIAD, the plans of the new Center of Excellence for Industry 4.0 Competence [8], and the research and the teaching efforts of the Center for Energy, Environment and Economy are all helping OzU to be one of the most impactful sustainable universities in Turkey and beyond.

ACKNOWLEDGEMENTS. We thank to a number of people at the University who helped us in preparing this short document. Prof. Dr. Hulya Turgut has been leading the work of the Sustainable Development Forum since 2017. Ms. Nergis Uyan is the Director of SCOLA, who has been responsible for implementing and tracking the sustainability initiatives at ENG courses. Ms. Gokce Ersel, who is studying Sustainable City concept at the College of Architecture under M.P. Mengüç is to be credited with streamlining the details provided in this document.

\section{References}

1. Ozyegin University Foundation History, Retrieved March 30, 2017, from https://www.ozyegin.edu.tr/en/about-us/foundationhistory (2017).

2. Center for Energy, Environment and Economy (CEEE) at Ozyegin University, Retrieved March 30, 2017 https://ecem.ozyegin.edu.tr/en (2017).

3. UN Sustainable Development Goals, retrieved from http://unsdsn.org/what-we-do/sustainabledevelopment-goals/about-the-sdgs/ (2017).

4. New Energy Efficiency Demonstration For Buildings, NEED4B, EU-FP-7 Project, Retrieved March 30, 2017, from http://www.need4b.eu/ (2017).

5. School of Languages, SCOLA, Ozyegin University, Retrieved March 30, 2017, https://www.ozyegin.edu.tr/en/school-languagesscola, (2017).

6. Zero-Istanbul 2050 Initiative, CEEE, Ozyegin University, Retrieved March 30, 2017, https://www.ozyegin.edu.tr/en/etkinlikler/50015023 (2010).

7. Ozyegin University, Technology Transfer Ofisi, OzU-TTO, Retrieved March 30, 2017, http://tto.ozyegin.edu.tr/en (2017). 
8. Ozyegin University "Digital Transformation of SMEs in Turkey through Establishment of the Industry 4.0. Competence Center", Retrieved March 30, 2017, https://www.ozyegin.edu.tr/en/announcements/235 8/our-industry-40-competence-center-projectadmitted-into-the-priority-group-to-receive-funding (2017).

9. Schneider Go Green in the City, Women in Business Award. Retrieved from https://www.schneider-
electric.com/ww/en/documents/Press/2017/08/09release-go-green-in-the-city-tcm50-323141.pdf (2017).

10. Elsevier JQSRT Viskanta Young Scientist Awards, Retrieved March 30, 2017, https://www.journals.elsevier.com/journal-ofquantitative-spectroscopy-and-radiativetransfer/awards-winners/winners-of-the-2017elsevierjqsrt-raymond-viskanta-awards-el (2017). 